\title{
Impact of biomechanics-based activities on situational and individual interest among K-12 students
}

\section{Prof. Carrie A Francis, University of Northwestern-St. Paul}

Carrie Francis is an Assistant Professor of Engineering at the University of Northwestern-St. Paul. She received her Ph.D. in Biomedical Engineering from the University of Wisconsin-Madison. She has previously received degrees in biomedical engineering from Washington University in St. Louis (B.S.) and the University of Wisconsin-Madison (M.S.). Her teaching interests include general physics, statics \& dynamics, and mechanics of materials. Her disciplinary research focuses on walking and balance in old adults with an emphasis on gait variability and rehabilitation. Her interests include outreach to K12 students and improving science literacy among non-STEM major students.

\section{Mr. Joseph E Michaelis, University of Wisconsin, Madison}

Joseph E Michaelis is a Ph.D. student in Educational Psychology in the Learning Sciences area at the University of Wisconsin - Madison. His research involves studying interest in STEM education, focusing on the impact of learning environments, feedback, and influence of social constructs and identities. This research includes developing inclusive learning environments that promote interest in pursuing STEM fields as a career to a broad range of students.

\section{Mr. Samuel Alberto Acuña, University of Wisconsin-Madison}

Samuel Acuña is Ph.D. candidate in the Mechanical Engineering department at the University of Wisconsin-Madison, where he studies neuromuscular biomechanics. He aims to improve gait and balance in older adults by developing technology that influences the nervous system. Samuel received his BS in Mechanical Engineering from Brigham Young University in 2012, and his MS in Mechanical Engineering from the University of Wisconsin-Madison in 2015.

\section{Dr. Joseph Towles, University of Wisconsin, Madison}

Joseph Towles is a faculty associate in the Department of Biomedical Engineering at the University of Wisconsin-Madison. Joe completed his PhD in the Department of Mechanical Engineering at Stanford University and a research post-doctoral fellowship in the Sensory Motor Performance Program at the Rehabilitation Institute of Chicago and in the Department of Physical Medicine and Rehabilitation at Northwestern University. His teaching and research interests are in the areas of engineering education and neuromuscular biomechanics. With respect to engineering education, Joe focuses on assessment and evaluation of student learning; and innovation and research in approaches to enhance student learning. Concerning neuromuscular biomechanics, Joe's research interests are in translational studies aimed at elucidating the mechanics and control of the hand following neurologic and musculoskeletal injury with the goal of developing innovative rehabilitative and surgical interventions that improve grasp function. Computational and experimental approaches are used to investigate intrinsic characteristics of muscles, neuromuscular control and sensorimotor integration in the context of functional restoration of grasp. 


\section{Impact of biomechanics-based activities on situational and individual interest among K-12 students}

\section{Introduction}

Engineering remains a field with disproportionately low representation of women and individuals from underrepresented minority (URM) groups. As early as middle school, these groups start losing interest in science, technology, engineering and math (STEM) fields (National Science Foundation, 2004; Driver, 1985). Thus, early interventions that spark interest and encourage pursuit of STEM areas are greatly needed. Biomechanics is a highly relatable, interdisciplinary field with ties to engineering, medicine, and athletics. In a previous study (Francis et al., 2016), we found biomechanics-based activities had potential for teaching biomechanics to $5^{\text {th }}-8^{\text {th }}$ grade students with presumably varying interest levels and demographic backgrounds. Our current study investigated the impact of similar biomechanics-based activities on situational and individual interest among K-12 students while considering gender, grade-level, and ethnicity.

\section{Methods}

\section{Protocol}

We surveyed students attending an engineering outreach event before and after participating in up to seven interactive biomechanics activities. The activities were as follows: (1) measurement of maximum jump height using a Microsoft Kinect system (Redmond, WA) for comparison to professional athletes and animals; (2) measurement of walking characteristics using Wii Balance Boards (Nintendo; Redmond, WA); (3) measurement of muscle activity using surface electrodes (Back Yard Brains; Ann Arbor, $\mathrm{MI})$; (4) investigating object properties in a virtual reality (VR)

\section{Pre-Activities Statements/Questions}

1. I enjoy learning about engineering even when it is very difficult

2. I work on projects that are like engineering outside of school at least once a week

3. Knowing about engineering is extremely valuable to me

4. I know way more about engineering than other kids I know

5. Compared to other students at my school, I am way better at doing engineering work

6. I might want to be an engineer when I grow up

\section{Post-Activities Statements/Questions}

1. I think this demonstration was very exciting

2. After visiting the lab, I would like to learn more about engineering

3. What we learned in this lab is useful for me to know

4. I might want to be an engineer when I grow up

5. To me, the activities in this lab were very entertaining

6. I'd like to learn more about the topics we learned about in this lab

7. I learned valuable things during the demonstration

8. What grade are you in

9. What is your gender

10. What is your race/ethnicity

Figure 1: Pre- and Post-Activities Statements/Questions.

environment using a haptic robot and VR system; (5) generation of spiral bone fractures in lower limb chicken bones; (6) measurement of basketball dribbling characteristics with a smart basketball (InfoMotion Sports Technology; Dublin, $\mathrm{OH}$ ); and (7) investigating human walking 
patterns using a computer simulation of gait (BioMotion Laboratory, Queens University; Kingston, Ontario, Canada). In activity \#1, each participant was asked to jump as high as possible over a series of three trials and their height was displayed with others who participated that day. In activity \#2, vertical ground reaction force was measured and displayed as each participant attempted novel walking patterns to manipulate the force. In activity \#3, electrical activity in muscle was measured and displayed as each participant attempted to modulate the signal through various muscle contraction patterns. In activity \#4, each participant explored objects in a virtual environment using a three degree-of-freedom haptic interface. In activity \#5, each participant learned about why bones break, different types of bone fractures before having an opportunity to induce a spiral fracture in a lower limb chicken bone using a hand drill. In activity \#6, each participant dribbled an instrumented basketball for a max number of dribbles in 20 sec. Finally, in activity \#7, each participant guessed traits (e.g., happy, frustrated, male, female) of a computer simulation of a human walking.

The outreach event pre- and post-surveys, consisting of questions rated on a 7-point scale ( $1=$ strongly disagree, $7=$ strongly agree), were designed to measure individual and situational interests in sub-sets of students self-identified by gender, grade level, ethnicity and initial interest in engineering. The pre-survey questionnaire consisted of five individual interest questions (items \#1-5) which were modified from Michaelis and Nathan (2015). The post-survey questionnaire consisted of six situational interest questions (items \#1-3 \& 5-7) which were modified from Knogler et al. (2015). Individual interest is defined as an enduring predisposition to engage and re-engage with specific content, characterized by relatively high levels of positive affect, value and knowledge for the content (Hidi and Renninger, 2006). Situational interest is a psychological state that is generated in the moment and characterized by focused attention and effort on a task (Hidi and Renninger, 2006). While the surveys were designed to gauge individual and situational interest levels on the part of the participants, they were not designed to explicitly assess participants' understanding of engineering per se. Pre-participation questions were printed on one side of a piece of paper; post-participation questions were printed on the reverse (Fig. 1).

\section{Data Analyses}

Individual interest scores were calculated by averaging the scores of the five individual interest items on the pre-survey questionnaire. Situational interest scores were calculated by finding the average of the scores of the six situational interest items on the post-survey questionnaire. Interest in an engineering career was assessed based on the scores of items \#6 and \#4 on the pre- and postsurvey questionnaires, respectively. The threshold for low and high levels of interest were determined by the range of values less than and greater than the mean for that interest.

An ANOVA test $(a l p h a<0.05)$, conducted using $R$, was used to compare individual and situational interest levels pre- and post- and as functions of demographic factors. Where appropriate, $t$-tests $($ alpha $<0.05)$ were used as post-hoc tests when significance occurred following the ANOVA test. 


\section{Results}

Over two-days, we collected 607 completed surveys (82\% of total, Table 1) from students. 52\% were female and $20 \%$ were members of an URM group. Before participating in the biomechanics-

Table 1: Individual and Situational Interest, and Pre-/Post- Career Interest by Demographic Categories.

\begin{tabular}{ccccccc} 
& & $\mathrm{n}$ & $\begin{array}{c}\text { Individual } \\
\text { Interest (SD) }\end{array}$ & $\begin{array}{c}\text { Situational } \\
\text { Interest (SD) }\end{array}$ & $\begin{array}{c}\text { Pre-Career } \\
\text { Interest }\end{array}$ & $\begin{array}{c}\text { Post-Career } \\
\text { Interest }\end{array}$ \\
\hline Gender & Boys & 293 & $4.46(1.79)$ & $5.59(1.07)$ & $4.87(1.89)$ & $5.06(1.82)$ \\
& Girls & 314 & $3.90(1.29)$ & $5.29(1.24)$ & $3.94(2.00)$ & $4.32(2.02)$ \\
Race & & & & & & \\
& Not Indicated & 1 & $4.4(\mathrm{NA})$ & $5.83(\mathrm{NA})$ & $6.00(\mathrm{NA})$ & $7.00(\mathrm{NA})$ \\
& White & 456 & $4.22(1.28)$ & $5.45(1.16)$ & $4.42(1.98)$ & $4.71(1.93)$ \\
& Hispanic/Latino & 55 & $3.74(1.11)$ & $5.35(1.04)$ & $4.38(2.02)$ & $4.47(2.12)$ \\
& African-American & 20 & $3.63(1.36)$ & $5.10(1.08)$ & $3.45(2.24)$ & $3.90(2.05)$ \\
& Native American & 2 & $2.80(0.57)$ & $6.42(0.35)$ & $5.00(1.41)$ & $5.5092 .12)$ \\
& Asian/Pacific & 43 & $4.49(1.05)$ & $5.41(1.35)$ & & \\
& Islander & & & & \\
& Other & 15 & $4.17(1.27)$ & $5.22(1.39)$ & $4.67(2.03)$ & $4.81(1.95)$ \\
& Multiple Selected & 15 & $4.20(1.64)$ & $5.72(1.45)$ & $4.13(2.13)$ & $4.93(2.05)$ \\
& & & & & & \\
Grade & Elementary (K - 5) & 307 & $4.14(1.20)$ & $5.47(1.20)$ & $4.26(1.98)$ & $4.56(1.94)$ \\
& Middle (6-8) & 267 & $4.09(1.33)$ & $5.33(1.14)$ & $4.40(2.04)$ & $4.69(1.99)$ \\
& High (9-12) & 31 & $5.23(0.80)$ & $5.98(0.82)$ & $5.74(1.26)$ & $5.87(1.31)$ \\
& Post-Secondary & 2 & $3.80(3.39)$ & $4.5(3.06)$ & $4.00(4.24)$ & $4.00(4.24)$ \\
\hline Total & & 607 & $4.17(1.27)$ & $5.43(1.17)$ & $4.39(2.01)$ & $4.68(1.96)$ \\
\hline
\end{tabular}

based activities, we found that boys $(t(606)=5.56, p<0.05)$ had higher individual interest in engineering than girls. After participating, the number of boys and girls who indicated they would pursue a career in engineering increased significantly, though the effect size was small $(t(606)=6.06, p<0.05, d=0.14)$. Specifically, students who indicated low individual interest accounted for that increase $(d=0.22)$. We also found that boys and girls with high individual interest experienced the same level of situational interest $(t(316)=0.37, p=0.71$, Fig. 2$)$. Boys with low individual interest, however, experienced marginally significantly greater situational interest than girls with low individual interest $(t(288)=2.61, p=0.07$, Fig. 2). 


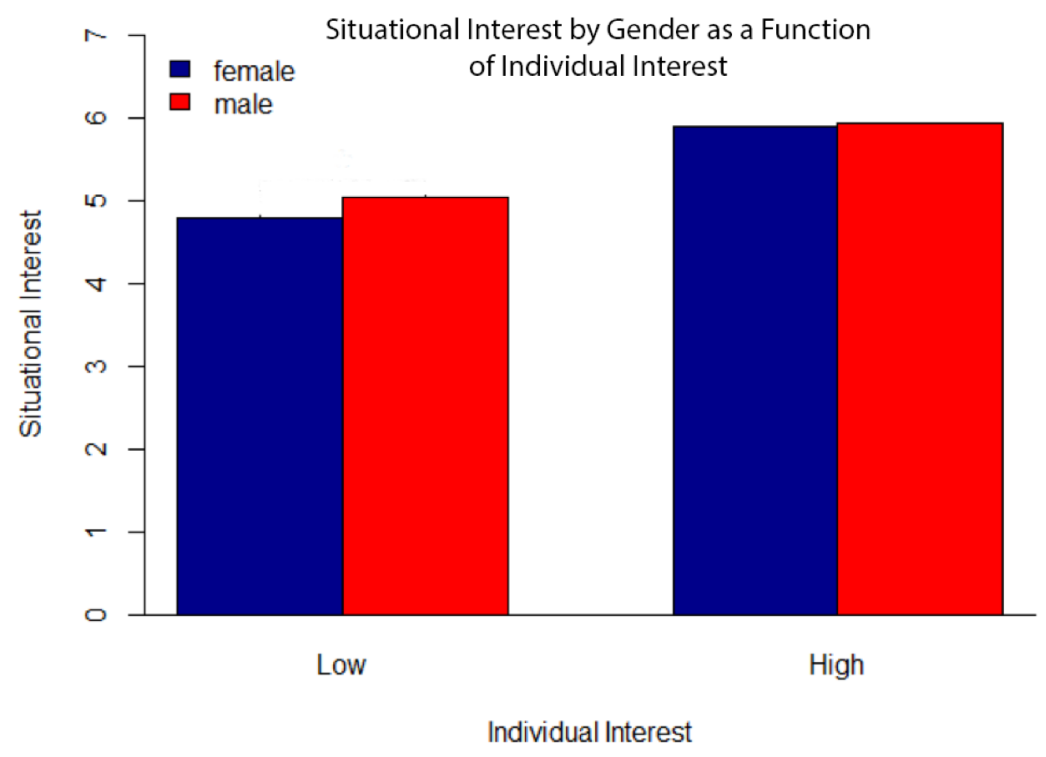

Figure 2: Change in Situational Interest by Gender for Varying Levels of Individual Interest. Situational interest for low individual-interest boys is marginally significantly higher for boys than girls $(p=0.07)$. Situational interest levels for high individual-interest boys and girls are the same $(p=0.71)$. The threshold for low vs. high individual interest level was the mean level (4.12). That is, all values below the mean were associated with low individual interest; and all values above the mean, high individual interest.

\section{Discussion}

Engineering remains a field with disproportionately low representation of women and individuals from under-represented minority (URM) groups. Consequently, any effort to develop an interest or to grow a pre-existing interest in STEM in diverse student groups at early educational stages is worthwhile pursuing. In this study, we explored the impact of biomechanics-based activities on situational and individual interest among K-12 students while considering gender, grade-level and ethnicity. Our results suggest that biomechanics-based activities can engage students at high and low levels of interest in biomechanics, similar to the finding from a previous study in our group (Francis et al., 2016), and can positively impact their consideration of careers in engineering. We were unable to engage low individual-interest girls more than boys, and ethnicity and grade-level were not influential factors.

This study was performed at an engineering outreach event that was primarily attended by students from schools throughout the state of Wisconsin. The percentages of female (52\%) and URM (20\%) student group participants were generally consistent with the proportion of those groups in K-12 Wisconsin public schools (Wisconsin Public School Enrollment, 2015). The finding that boys had higher individual interest in engineering than girls is consistent with well-supported observations from other studies (e.g., Stoet et al., 2016). In a mixed-gender group of 761,655 fifteen year-olds from nearly 70 countries, Stoet and colleagues found that girls had higher anxiety 
toward mathematics than boys. This observation was unaffected by the level of the mother's engagement in STEM, the developmental level of the country and the level of gender equality in the country. A broader view of the literature indicates that the source of discrepancy in individual interest between girls and boys is debatable. Other studies cite fewer STEM-related educational opportunities (Tolley, 2003) for girls and gender stereotypes (Bieg et al., 2015) as possible sources.

The observation that our study could affect a student's consideration of engineering as a career choice was not surprising. Children are impressionable and childhood experiences have been shown to be critical in how a child thinks or feels about a career choice (Watson, McMahon, 2005). Further, studies have shown that specific, early career-related, impressionable childhood experiences can persist to the forming of the actual career choices (Trice, 1991; Trice, McClellan, 1993).

As to the relationship between individual and situation interests (Fig. 2), it is unclear why boys and girls with high individual-interest experienced the same level of situational interest when boys and girls with low individual-interest experienced marginally different levels of situational interest. Individual and situational interests may be related in a complex way. Additionally, the observation that low individual-interest boys experienced marginally higher situational interest than low individual-interest girls may have been due to intrinsic differences (e.g., gender stereotypes (Bieg et al., 2015), psychological factors (Stoet et al., 2016)) between boys and girls that are more pronounced or influential at low individual-interest levels. The relationship between individual and situational interest levels and the influence of gender warrant additional investigation in future studies.

For the sample size tested (607), we were surprised that ethnicity and grade-level were not factors in this study. Perhaps this relates to variability in the data or the possibility that participants experienced a different mix of biomechanics-based activities. No instructions were given as to which and how many activities to pursue. From an experimental design perspective, a lack of influence of student ethnicity and grade-level could relate to the activities chosen or the demographics of the facilitators. For example, it is challenging to believe that individual and situational interests of K-5 students (4.14 (1.20) and 5.47 (1.20)) will always be the same as that for high school students $(5.23(0.80)$ and $5.98(0.82))$ given emotional and psychological factors. Future studies will aim to explore the possible effects of activity facilitator demographics, employing different biomechanics-based activities, and standardizing the number and specific activities that participants experience.

\section{References}

Wisconsin Public School Enrollment. 2015; Available from https://dpi.wi.gov/cst/datacollections/student/ises/published-data/excel.

Bieg M, Goetz T, Wolter I, Hall NC. Gender Stereotype Endorsement Differentially Predicts Girls' and Boys' Trait-State Discrepancy in Math Anxiety. Frontiers in Psychology, 6, 2015.

Driver R. Children's Ideas and the Learning of Science. Children's Ideas in Science. Philadelphia, PA, Open University Press: 1-9, 1985. 
Francis, C, Franz, J, Leinhart, R, Kaiser, J, Towles, J. Work in Progress: Evaluation of Biomechanics Activities at a College-Wide Engineering Outreach Event. Proceedings of the Annual Conference of the American Society of Engineering Education, New Orleans, LA, 2016.

Hidi, S and Renninger, KA. The Four Phase Model of Interest Development. Educational Psychologist, 41, 111-127, 2006.

Knogler, M, Harackiewicz, JM, Gegenfurtner, A, Lewalter, D. How Situational is Situational Interest? Investigating the Longitudinal Structure of Situational Interest. Contemporary Educational Psychology, 43, 39-50, 2015.

Michaelis, JE and Nathan, MJ. The Four-Phase Interest Development in Engineering Survey. Proceedings of the Annual Conference of the American Society of Engineering Education, Seattle, WA, 2015.

National Science Foundation. Women, Minorities, and Persons with Disabilities in Science and Engineering. Arlington, VA: Arlington, VA: National Science Foundation, 2004.

Stoet G, Bailey D, Moore AM, Geary DC. Countries with Higher Levels of Gender Equality Show Larger National Sex Differences in Mathematics Anxiety and Relatively Lower Parental Mathematics Valuation for Girls. PLOS One, DOI:10.1371, 2016.

Tolley K. The Science Education of American Girls: A Historical Perspective. London: Routledge, 2003.

Trice, AD and McClellan, N. Do Children's Career Aspirations Predict Adult Occupations? An Answer from a Secondary Analysis of a Longitudinal Study. Psychological Reports, 72, 368-370, 1993.

Watson, M and McMahon, M. Children's Career Development: A Research Review from a Learning Perspective. Journal of Vocational Behavior, 67, 119-132, 2005. 